\title{
Selective Harmonic-Compensation Control for Single-Phase Active Power Filter With High Harmonic Rejection
}

\author{
Jaume Miret, Member, IEEE, Miguel Castilla, José Matas, \\ Josep M. Guerrero, Senior Member, IEEE, and Juan C. Vasquez
}

\begin{abstract}
This paper presents a linear current control scheme for single-phase active power filters. The approach is based on an outer voltage loop, an inner current loop, and a resonant selective harmonic compensator. The design of the control parameters is carried out using conventional linear techniques (analysis of loop gain and other disturbance-rejection transfer functions). The performance of the proposed controller is evaluated and compared with two reference controllers: a basic control and an advanced repetitive control. In comparison with these controllers, the proposed control scheme provides additional attenuation to the harmonics coming from the load current, the grid voltage, and the reference signal, resulting in a grid current with lower harmonic distortion. Experimental results are reported in order to validate this paper.
\end{abstract}

Index Terms-Active power filter (APF), harmonics, power quality, selective compensation.

\section{INTRODUCTION}

$\mathbf{N}$ OWADAYS, the amount of harmonic currents flowing into the grid is growing rapidly due to polluting loads. Some power-line-conditioner methods have been proposed in the literature to minimize harmonic-distortion currents [1]-[5]. One of the most popular power line conditioners is the active power filter (APF) [3]-[12]. The shunt solution is the most widely used in low- and medium-power applications due to simplicity, effectiveness, and harmonic-rejection capabilities. Shunt filters are usually applied to three-phase systems where a large capacity is required. However, single-phase active filters can be applied in adjustable-speed motor drives fed by a singlephase utility, in air-conditioning systems, or in rural areas supplied by a single-wire with Earth-return power system.

The main purpose of the shunt APF system is to supply the harmonics absorbed by the nonlinear load, in order to provide the grid current with a low-harmonic content. To this end, the control of APF systems has been widely studied in the literature. The basic approach consists of two control loops.

Manuscript received September 10, 2008; revised May 26, 2009. First published June 10, 2009; current version published July 24, 2009. This work was supported by the Spanish Ministry of Science and Technology under Grant ENE2006-15521-C03-01.

J. Miret, M. Castilla, and J. Matas are with the Department of Electronic Engineering, Technical University of Catalonia, 08800 Vilanova i la Geltrú, Spain (e-mail: jmiret@eel.upc.edu; mcastilla@eel.upc.edu; matasalc@gmail.com).

J. M. Guerrero and J. C. Vasquez are with the Department of Automatic Control Systems and Computer Engineering, Technical University of Catalonia, 08036 Barcelona, Spain.

Digital Object Identifier 10.1109/TIE.2009.2024662
The outer voltage loop is responsible for capacitor-voltage regulation while the inner current loop performs the referencecurrent-signal tracking. For the reference-signal generation, the direct method consists of sensing the load current and extracting the harmonic content. Then, the filter current is used in the inner current loop in order to track the load current harmonics [6], [7]. As an alternative, the indirect method generates a sinusoidal reference signal by means of grid-voltage sensing. In that case, the grid current is forced to follow this sinusoidal signal, and thus, the load harmonics are indirectly given by the APF inductor current [9]-[12]. The main advantages of this second approach are that only one low-bandwidth current sensor is required and faster transient response is obtained [12].

In order to improve the performance of the inner current loop, optimal, neural, and model reference adaptive controls have been used recently [13]-[15]. Other approaches utilize nonlinear regulators, such as sliding-mode control and hysteretic control [16], [17]. All the previously mentioned controls attenuate the current harmonics only to a certain level. Forcing the current control to further reduce some remaining harmonics can bring the system to instability [18].

Selective harmonic compensation has been introduced in order to reduce significantly the harmonics chosen by the designer [18]-[23]. Within this approach, the more harmful harmonics from the load current, which are not sufficiently attenuated with other control schemes, can be almost completely compensated for. The main idea behind this technique is to generate a reference current by the usual method and, then, to process their harmonics individually. A new reference current is then produced with information about the most problematic harmonics that need to be eliminated. With this technique, the filter rating, the current-control bandwidth, and dangerous interactions with system resonances are reduced [5]. It is worth mentioning that this technique has been successfully applied to single- and three-phase APF applications.

Repetitive control has been used in the past to implement suitable selective harmonic compensators [20], [21]. This type of control includes the internal model in the closed-loop system to assure low error in steady state. In [20], an interesting repetitive-control scheme with high harmonic-rejection capability is presented. In that study, the reference signal is generated using an indirect method. The grid voltage and current are sensed and processed using a comb filter with unity gains, both at the fundamental and at some chosen harmonics. However, a 
drawback of this technique is that it requires of some additional algorithms in order to avoid distortion coming from the grid voltage.

As an alternative approach, linear resonant harmonic compensators have been recently presented [24]-[32]. These compensators consist of several generalized integrators, i.e., second-order bandpass filters with high gain and low bandwidth. Each generalized integrator is responsible for the attenuation of a specific current harmonic, so that each bandpass filter is tuned to resonate at an odd multiple of the grid frequency. Normally, these bandpass filters do not affect the dynamics of the inner current loop due to the low bandwidth. This is an interesting feature in applications where fast dynamics and harmonic compensation are required, as, for example, photovoltaic inverters, front-end rectifiers, and APF systems.

This paper proposes a linear current control scheme for single-phase APFs. The control uses an indirect referencegeneration technique and a resonant selective harmonic compensator. The proposed control scheme gives high attenuation to the harmonics coming from the load current, the grid voltage, and the reference signal, resulting in a grid current with lower harmonic distortion. This paper is organized as follows. Section II describes the control configuration. Section III presents the design of the proposed control. Section IV verifies the expected features of the proposed controller by means of selected experimental results. In addition, a performance comparison with both a basic indirect current controller and the repetitive controller is provided. Section $\mathrm{V}$ presents the conclusions of this paper.

\section{INDIRECT CONTROL SCHEMES FOR THE Single-PHASE SHUNT APF}

This section reviews the indirect current-control method and presents three reference-current-generator schemes, including the basic approach, a repetitive control, and the proposed control.

\section{A. Indirect Current-Control Method}

Fig. 1 shows the typical configuration of a full-bridge APF circuit in parallel with both the grid and the nonlinear load. The main objective of the APF is to supply a current $i_{l}$ that, added to the load current $i_{o}$, produces a grid current $i_{s}$ without harmonic content. If $i_{l}$ is exactly the inverse of the harmonic content of $i_{o}$, the power factor of the grid current $i_{s}$ will be unitary.

Fig. 2 shows a general diagram of the indirect current-control method. The control is based on an outer voltage loop, a reference generator, and an inner current loop. Note that the indirect method uses the grid current in the inner current loop instead of the load current.

The outer voltage loop regulates the square of $v_{c}$ to a reference signal $v_{\text {ref }}^{2}$ with a simple PI compensator [33], [34]. Using the square of $v_{c}$ instead of $v_{c}$, the design of this loop is simpler, as discussed in Section III. The output of the PI compensator $k(t)$, which is related to the power consumed by the load, presents a slight ripple at twice the grid frequency. In

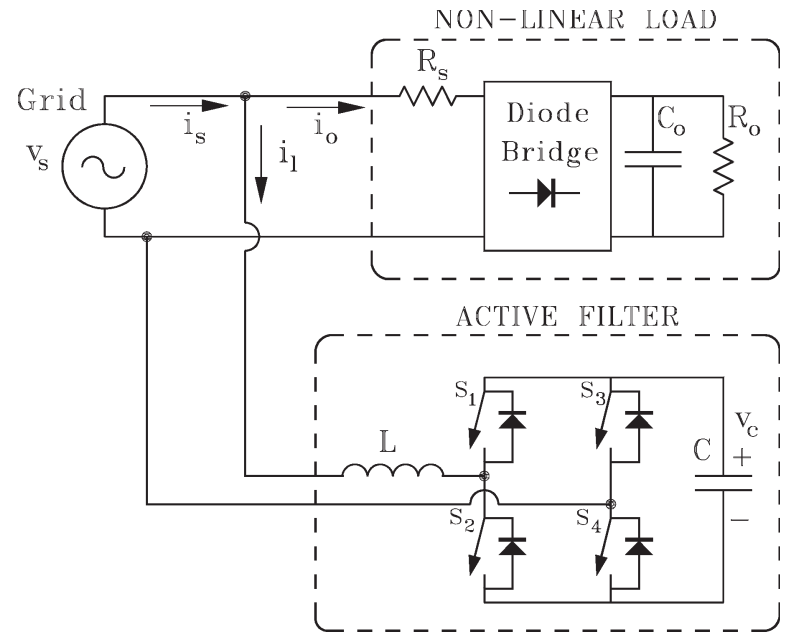

Fig. 1. Shunt APF: power circuit with the grid, the nonlinear load, and the full-bridge converter.

order to reduce this undesirable ripple, a low-pass filter with a cutoff frequency less than twice the line frequency is used (see Fig. 2).

The inner current loop is responsible for reference-current tracking. The grid current $i_{s}$ is sensed and subtracted from the reference current $i_{\text {sref }}$. Then, the current error $i_{e}$ is applied to a regulator, usually a PI compensator, which assures stability and low tracking error. The control signal $v_{\text {cont }}$ is the input of a pulsewidth-modulation modulator that drives the power switches. Three reference generators are described as follows.

\section{B. Basic Reference Generator}

The basic approach to generate the reference current consists of multiplying $k(t)$ by the sensed grid voltage $v_{s}$ [10], [12] [see Fig. 3(a)]

$$
i_{\text {sref }}=k(t) \cdot v_{s} \text {. }
$$

Using (1), the reference current will follow the shape and phase of the grid voltage. A disadvantage of this basic method is that $i_{\text {sref }}$ replicates the distortion of the grid voltage. To reduce the current-harmonic content, a phase-locked loop (PLL) can be used to generate a low-distorted signal in phase with the grid voltage. The shortcoming of using a PLL can be an increase in the controller computational load.

The harmonic content of the grid current comes from two sources: The major one is the inherent distortion from the nonlinear load current, while the other, with probably a minor contribution, is the distortion present in the grid voltage. The basic indirect control reduces the harmonic content considerably but only to a certain level.

Forcing the current control to further reduce some remaining load harmonics by means of incrementing the current PI control gains, $k_{p i}$ and $k_{i i}$, can bring the system to instability [18]. On the other hand, the distortion that is potentially contained in the grid voltage will be conveyed to $i_{s \text { ref }}$ and will remain in the generated grid current. 


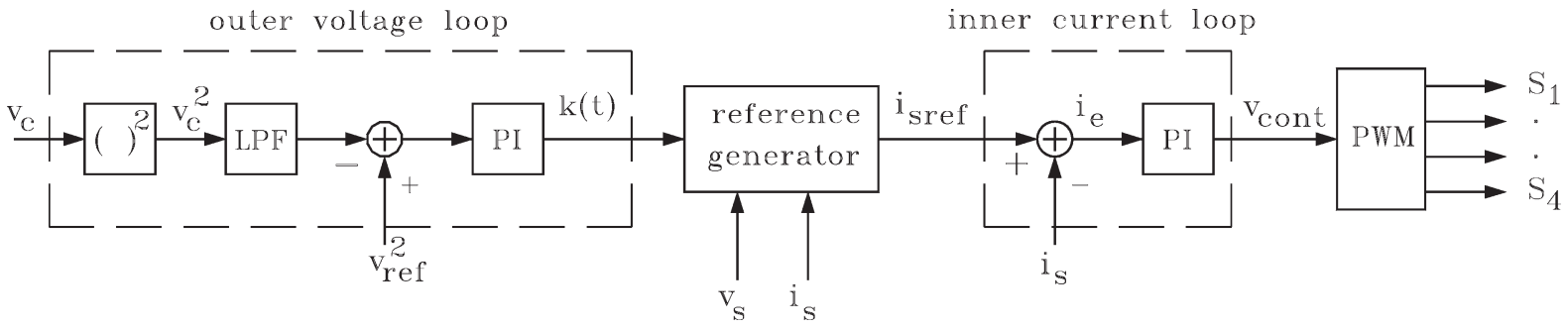

Fig. 2. General diagram of the indirect current-control method for single-phase APF.

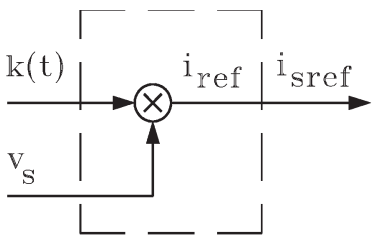

(a)

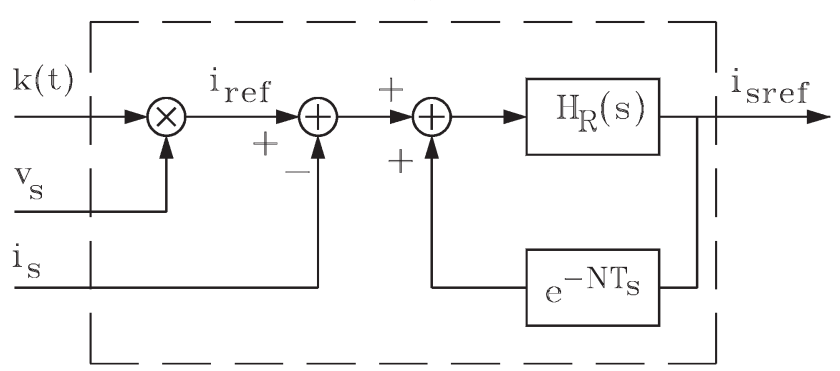

(b)

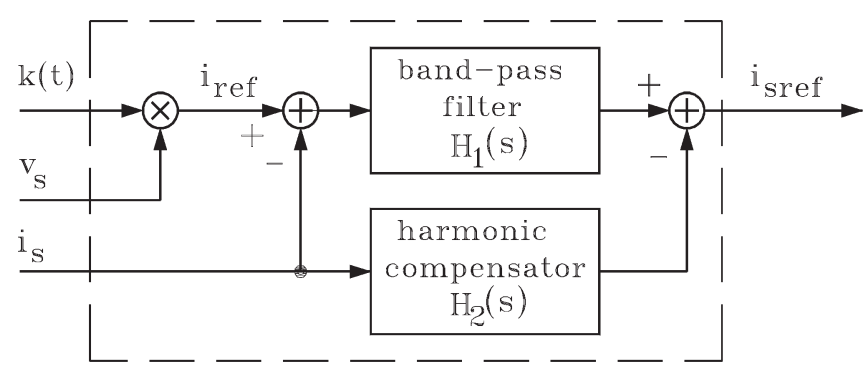

(c)

Fig. 3. Reference generators. (a) Basic control. (b) Repetitive control. (c) Proposed control.

\section{Reference Generator Based on Repetitive Control}

In order to overcome the earlier described drawbacks, an improved reference generator has been presented in [20]. Fig. 3(b) shows the diagram of this generator. As in the basic approach, a reference signal is generated by multiplying $k(t)$ by the sensed grid voltage $v_{s}$, but, now, this signal is processed by a repetitive controller. It is worth mentioning that this control scheme uses the generator output delayed by $N \cdot T_{s}$ (in seconds) as an input signal, where $N$ is an integer and $T_{s}$ is the sampling period. The transfer function $H_{R}(s)$ is a comb filter with resonances at the grid frequency and at some chosen harmonic frequencies. In this paper, $H_{R}(s)$ has been implemented as

$$
H_{R}(s)=H_{1}(s)+H_{2}(s)
$$

where $H_{1}(s)$ is a generalized integrator tuned to resonate at the grid frequency $f_{1}$ and $H_{2}(s)$ is a bank of generalized integrators tuned at odd multiples of the grid frequency.

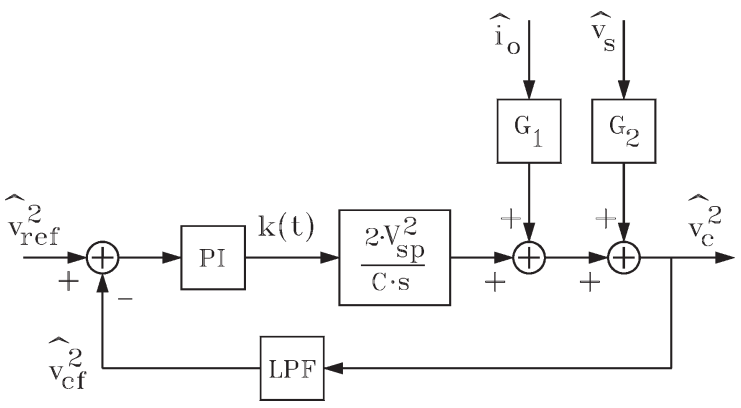

Fig. 4. Diagram of the outer voltage-loop small-signal model.

The generalized integrators can be expressed as

$$
\begin{aligned}
& H_{1}(s)=\frac{2 \xi \omega_{1} k_{1} s}{s^{2}+2 \xi \omega_{1} s+\omega_{1}^{2}} \\
& H_{2}(s)=\sum_{n=3}^{h} \frac{2 \xi n \omega_{1} k_{n} s}{s^{2}+2 \xi n \omega_{1} s+\left(n \omega_{1}\right)^{2}}
\end{aligned}
$$

where $\xi$ is the damping factor, $\omega_{1}=2 \pi f_{1}$, and $k_{1}$ is the gain at the fundamental frequency $f_{1} . n$ can take the values of $3,5, \ldots, h$, where $h$ is the highest current-harmonic component to be attenuated, and $k_{n}$ is the bandpass gain of each filter (more details of this controller can be found in [20]).

\section{Proposed Reference Generator}

As an alternative approach, a linear selective harmonic compensator is proposed in this section.

Fig. 3(c) shows the diagram of the proposed reference generator. This generator uses the same filters as the repetitive controller $H_{1}(s)$ and $H_{2}(s)$ but with a different interconnection. Note that the input of $H_{1}(s)$ is the error current (i.e., $i_{\text {ref }}-i_{s}$ ), and the input of $H_{2}(s)$ is the grid current $i_{s}$. In addition, it is worth mentioning that the output signals of both filters are now subtracted, and thus, the bandpass filters of $H_{2}(s)$ will behave in closed-loop operation as notch filters, as will be discussed in the next section.

\section{Control Design}

This section presents a systematic design for the proposed control scheme. A comparison with both the basic and repetitive controllers is also reported.

\section{A. Design of the Outer Voltage Loop}

Fig. 4 shows the diagram of the small-signal model of the outer voltage loop. The derivation of this model is described in 
TABLE I

SYSTEM PARAMETERS

\begin{tabular}{|c|c|c|}
\hline Symbol & Quantity & Value \\
\hline$v_{S}$ & grid voltage & $110 \mathrm{~V}$ \\
\hline$f_{1}$ & grid frequency & $60 \mathrm{~Hz}$ \\
\hline$S$ & nominal power & $500 \mathrm{VA}$ \\
\hline$f_{s}$ & switching frequency & $15 \mathrm{kHz}$ \\
\hline$R_{S}$ & non-linear load series resistance & $4 \Omega$ \\
\hline$R_{o}$ & non-linear load resistance & $90 \Omega$ \\
\hline$C_{o}$ & non-linear load capacitor & $500 \mathrm{uF}$ \\
\hline$L$ & active-filter inductance & $3.14 \mathrm{mH}$ \\
\hline$C$ & active-filter capacitance & $1.5 \mathrm{mF}$ \\
\hline$f_{c}$ & low-pass filter cross-over frequency & $10 \mathrm{~Hz}$ \\
\hline$k_{p v}$ & proportional voltage control gain & $1 e-6$ \\
\hline$k_{i v}$ & integral voltage control gain & $5 e-6$ \\
\hline$v_{\text {ref }}$ & capacitor reference voltage & $230 \mathrm{~V}$ \\
\hline$k_{p i}$ & proportional current control gain & 2 \\
\hline$k_{i i}$ & integral current control gain & $2 \cdot 10^{4}$ \\
\hline$h$ & considered harmonics & 9 \\
\hline$N$ & repetitive control delay steps & 2 \\
\hline \multirow[t]{2}{*}{$k_{n}$} & band-pass filters gain, repetitive control & 1 \\
\hline & band-pass filters gain, proposed control & 10 \\
\hline$\xi$ & band-pass filters damping factor & 0.01 \\
\hline
\end{tabular}

the Appendix. From the diagram, the voltage loop gain $T_{v}(s)$ can be expressed as

$$
T_{v}(s)=\left(k_{p v}+\frac{k_{i v}}{s}\right) \cdot\left(\frac{2 V_{s p}^{2}}{C s}\right) \cdot\left(\frac{\omega_{c}}{s+\omega_{c}}\right)
$$

where $k_{p v}$ and $k_{i v}$ are the gains of the PI regulator and $\omega_{c}=$ $2 \pi f_{c}$, where $f_{c}$ is the cutoff low-pass filter frequency. Note that the load current and the grid voltage are treated as external perturbations. $G_{1}(s)$ and $G_{2}(s)$ are the perturbations-to-outputsignal transfer functions.

From (5), it is evident that the gains of the PI regulator have a strong influence on the outer loop performance. These gains must be selected in order to achieve a slow capacitor-voltage transient response and a high stability margin. Usual design rules for grid-connected applications recommend the selection of the crossover loop-gain frequency $f_{c v}$ and the phase margin $\mathrm{pm}$ according to

$$
\begin{aligned}
f_{c v} & <\frac{f_{1}}{10} \\
30^{\circ} & <p m<60^{\circ} .
\end{aligned}
$$

The analysis of the loop-gain Bode plots, using the powercircuit parameters listed in Table I, reveals that several possible combinations of PI gains accomplish the conditions (6) and (7). The solution considered in this paper is based on the assumption of $f_{c v}=2.5 \mathrm{~Hz}$, i.e., less than an octave below the maximum allowed frequency, and a $56^{\circ}$ phase margin. The values for the PI gains are then collected from the Bode plot of the loop gain once $f_{c v}$ and $p m$ are specified. These values are listed in Table I.

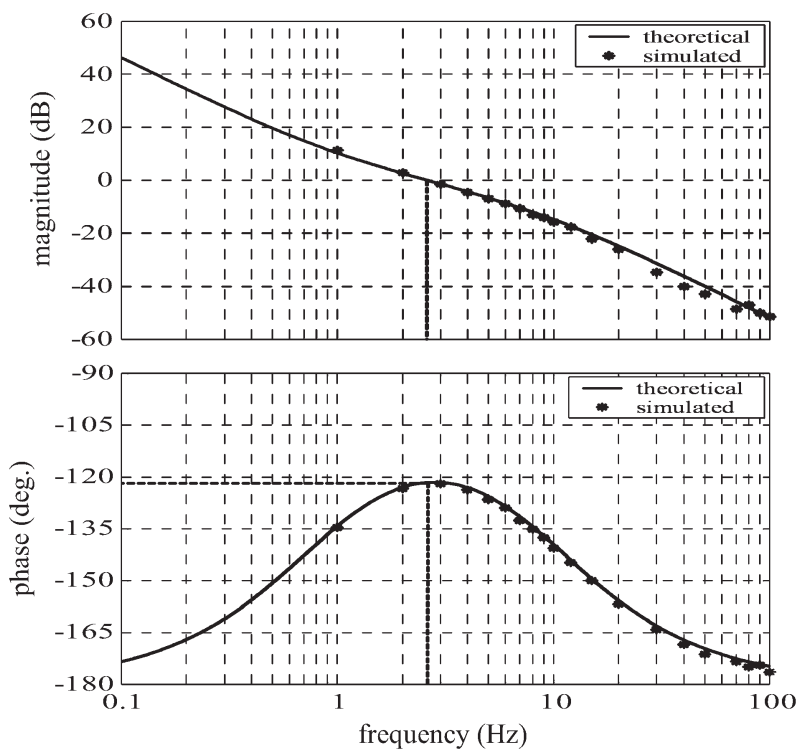

Fig. 5. Bode plot of the loop gain $T_{v}(s)$. Crossover frequency $=2.5 \mathrm{~Hz}$ and phase margin $=56^{\circ}$.

The theoretical study is validated using simulation results. The loop-gain transfer function has been measured using a frequency-response analyzer in a large-signal transient simulation environment. Fig. 5 shows the Bode plot of the loop gain, including the theoretical and simulation results. Note that these results show a high degree of similarity. Moreover, the expected voltage-loop requirements have been achieved.

\section{B. Design of the Inner Current Loop}

The design of the inner current loop requires a small-signal model of the APF system. This model must be accurate enough up to half the switching frequency in order to correctly describe the APF frequency characteristics. Some approximate models can be found in the literature [35], [36], but an exact model for frequencies higher than the grid frequency is not available yet. As an alternative, this paper uses simulation tools in order to design this control loop. In fact, the frequency characteristics of the inner current loop have been simulated using the frequencyresponse analyzer.

The frequency characteristics of the APF system can be extracted by evaluating four significant transfer functions. First of all, the current loop gain $T_{i}(s)$ is responsible for both the transient response and the stability of the APF system. The other transfer functions $G_{3}(s), G_{4}(s)$, and $G_{5}(s)$ are related to the system capability to reject external disturbances coming from the load current, the grid voltage, and the reference signal. In fact, the small-signal dynamics of the grid current can be expressed as

$$
\hat{i}_{s}(s)=G_{3}(s) \hat{i}_{o}(s)+G_{4}(s) \hat{v}_{s}(s)+G_{5}(s) \hat{i}_{\text {ref }}(s)
$$

where $G_{3}(s)$ is the load-current-to-grid-current transfer function, $G_{4}(s)$ is the grid-voltage-to-grid-current transfer function, and $G_{5}(s)$ is the reference-signal-to-grid-current transfer function.

The PI gains of the current loop have been designed following the same procedure, as described in Section III-A, for the 

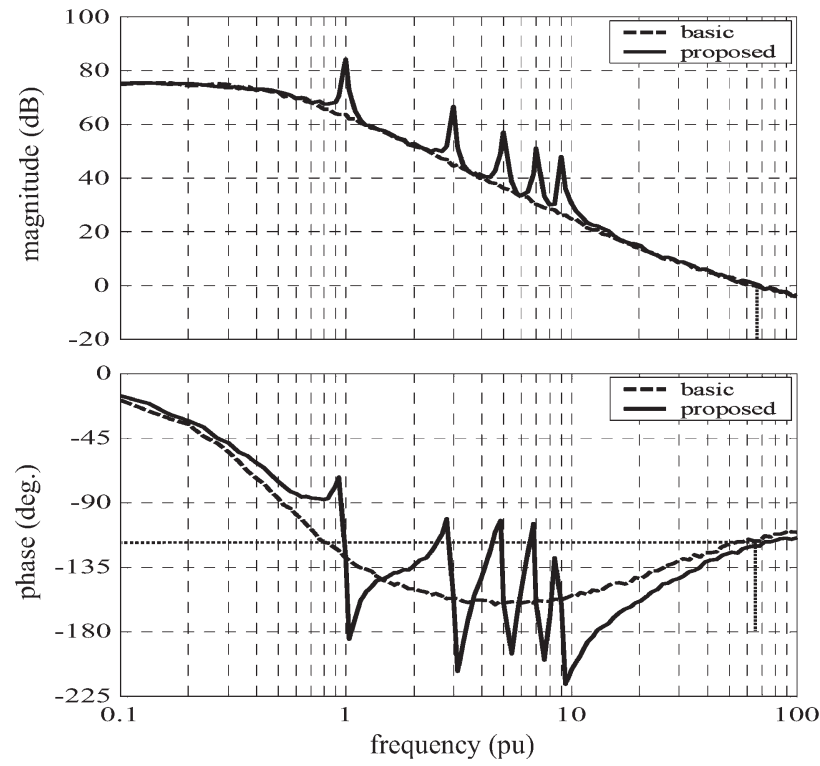

Fig. 6. Simulated frequency characteristics of the loop gain $T_{i}(s)$ using the basic and the proposed controllers. Crossover frequency $=4.2 \mathrm{kHz}$ and phase margin $=59^{\circ}$

voltage loop. Usual design rules for fast inner loops recommend to select the crossover frequency between $f_{s} / 6$ and $f_{s} / 3$ and a high phase margin for stability purposes. Fixing a crossover frequency of $4.2 \mathrm{kHz}$ and a phase margin of $59^{\circ}$, then the PI gains can be collected from the Bode plot of the current loop gain. These values are listed in Table I. Fig. 6 shows the current loop-gain Bode plots of both the proposed control scheme and the basic current controller. Note that the generalized integrators of the proposed controller produce a magnitude and phase deviation with respect to the basic control loop gain around their resonant frequencies. It is worth mentioning that the crossover frequency and the stability margin of both controllers are nearly equal, due to the low bandwidth of the bandpass filters (see Fig. 6).

The disturbance-rejection capability of the proposed controller is examined using the Bode plots of the transfer functions $G_{3}(s), G_{4}(s)$, and $G_{5}(s)$. Fig. 7 shows these transfer functions and also represents the transfer functions of the basic controller. As shown, the proposed controller introduces an additional attenuation $(20 \mathrm{~dB})$ at the selected harmonics (i.e., 3, 5, 7, and 9), thus increasing the harmonic-rejection capability. In $G_{5}(s)$, the attenuation given by the proposed controller is produced in the complete frequency range of interest, except at the fundamental frequency. In that case, the attenuation of the selected harmonics is very high, varying between 42 and $55 \mathrm{~dB}$. As shown in the figure, a low-harmonic content of the grid current is expected for the proposed controller.

The design of the generalized integrators is carried out using the previous figures. The additional attenuation at the selected harmonics is given by the bandpass gains $k_{n}$ (see Fig. 7). Although high attenuation can be desired, large PI gains reduce the phase loop gain at the crossover frequency, which can bring the system to instability (see Fig. 6). The damping factor $\xi$ must be chosen carefully. A low value is required in order to concentrate the effects of the bandpass filter in a narrow region

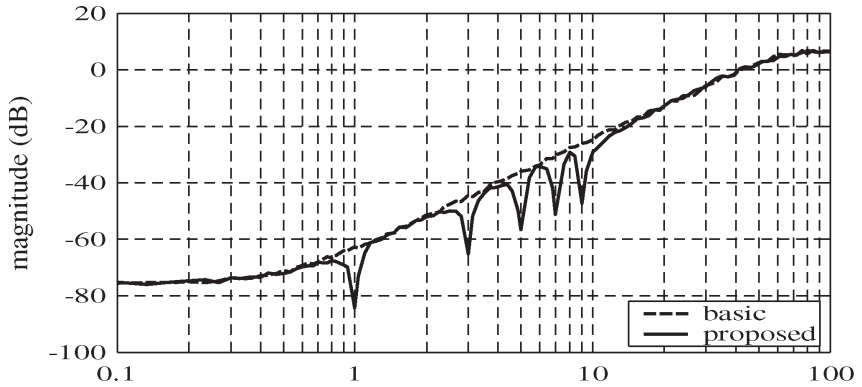

(a)

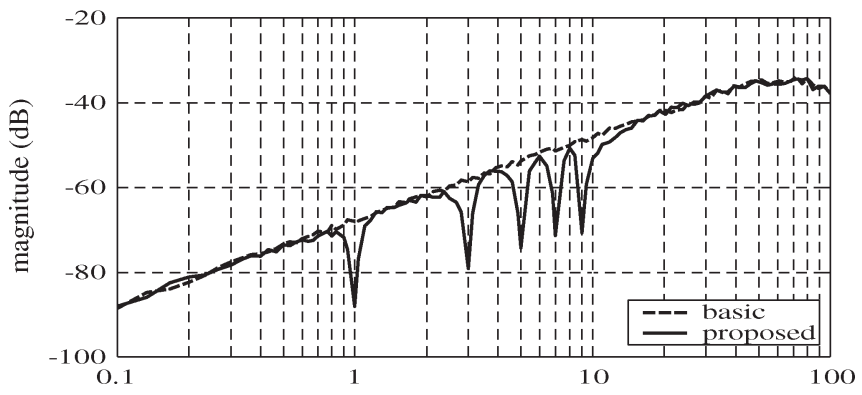

(b)

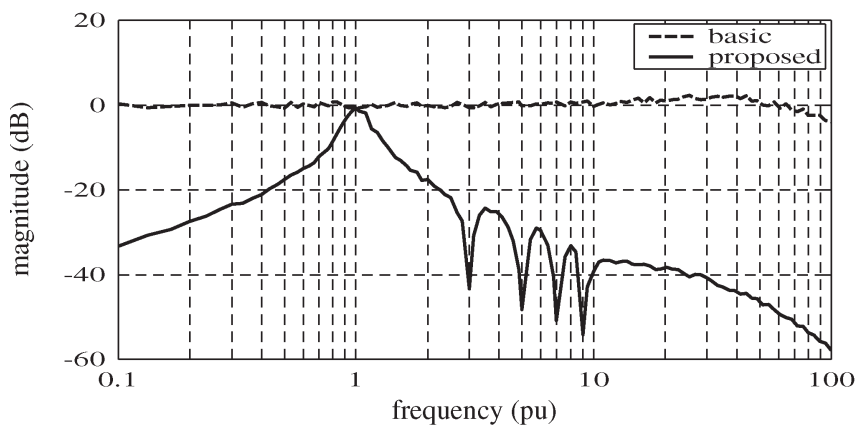

(c)

Fig. 7. Simulated frequency characteristics for both the basic and the proposed controllers. (a) $G_{3}(s)=i_{s} / i_{o}$. (b) $G_{4}(s)=i_{s} / v_{s}$. (c) $G_{5}(s)=$ $i_{s} / i_{\text {ref }}$.

around the harmonic frequencies. A high value is required when variations of the grid frequency are expected in order to preserve the harmonic rejection. The values of the generalized integrator parameters have been selected following this design tradeoff (see Table I).

\section{Comparison With the Repetitive Control}

In this section, the performance of the selective harmonic compensator based on repetitive control is compared with the proposed controller. Fig. 8 shows the transfer functions $G_{3}(s)$, $G_{4}(s)$, and $G_{5}(s)$ for both controllers.

As shown in Fig. 8(a), both controllers introduce additional attenuation $(20 \mathrm{~dB})$ in relation to the basic control at the selected harmonic frequencies (see also Fig. 7). At the fundamental frequency, the repetitive controller has a $0-\mathrm{dB}$ magnitude gain, indicating that the grid current will track the first harmonic of the load current. The proposed controller exhibits a high attenuation at that frequency, which shows a different operation principle. In this controller, all significant harmonics from the load are substantially rejected, including the fundamental one. 


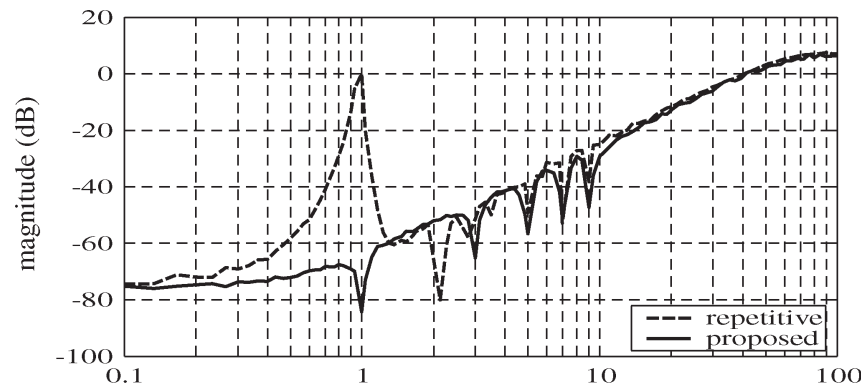

(a)

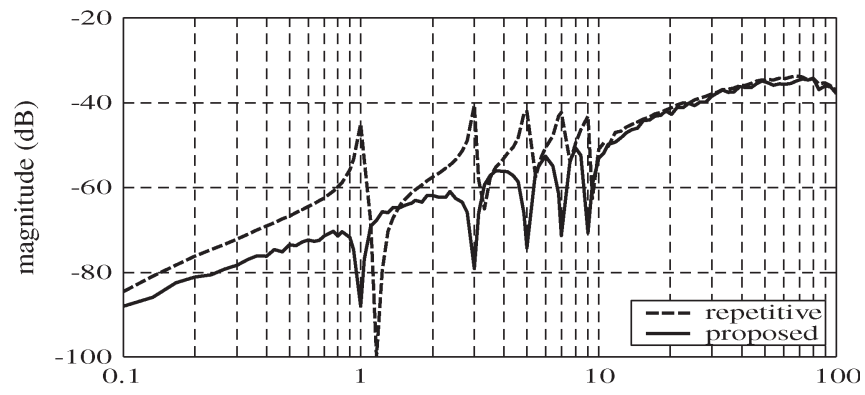

(b)

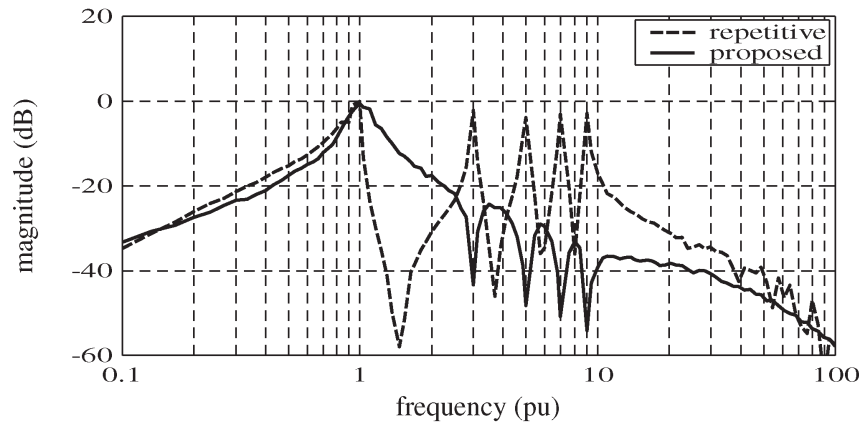

(c)

Fig. 8. Simulated frequency characteristics for both the repetitive and the proposed controllers. (a) $G_{3}(s)=i_{s} / i_{o}$. (b) $G_{4}(s)=i_{s} / v_{s}$. (c) $G_{5}(s)=$ $i_{s} / i_{\text {ref }}$.

In $G_{4}(s)$, a similar behavior is observed for both controllers. The main difference is that the proposed controller provides a higher attenuation at the fundamental frequency, i.e., its rejection capability against grid-voltage disturbances is superior.

The operation principle of both controllers is finally clarified with the Bode plot of $G_{5}(s)$. The proposed controller has a 0 -dB magnitude gain at the fundamental frequency, showing that the grid current will track the first harmonic of the reference current. In addition, the selected harmonics of the reference current have a high attenuation (more than $40 \mathrm{~dB}$ ). It is very interesting to observe [Fig. 8(c)] that the repetitive controller has $0-\mathrm{dB}$ magnitude gain at the selected harmonic frequencies. In that case, the harmonics of the reference current are directly conveyed to the grid current. In order to reduce the grid-current THD, a harmonic-free reference signal is required with the repetitive-control approach.

\section{EXPERIMENTAL RESUlts}

In this section, some experimental results are provided to validate the proposed control. A performance comparison with the conventional and the repetitive-control scheme is also reported.

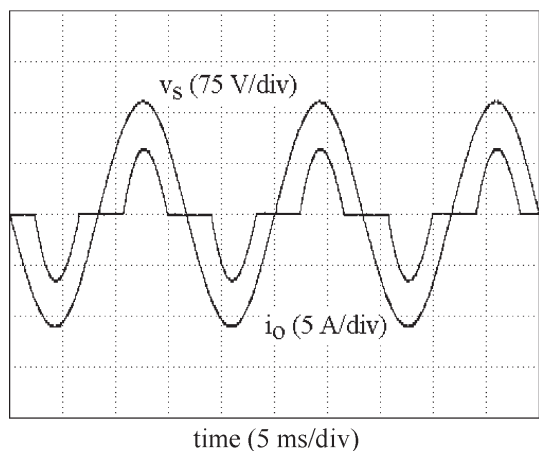

Fig. 9. Grid voltage and load current.

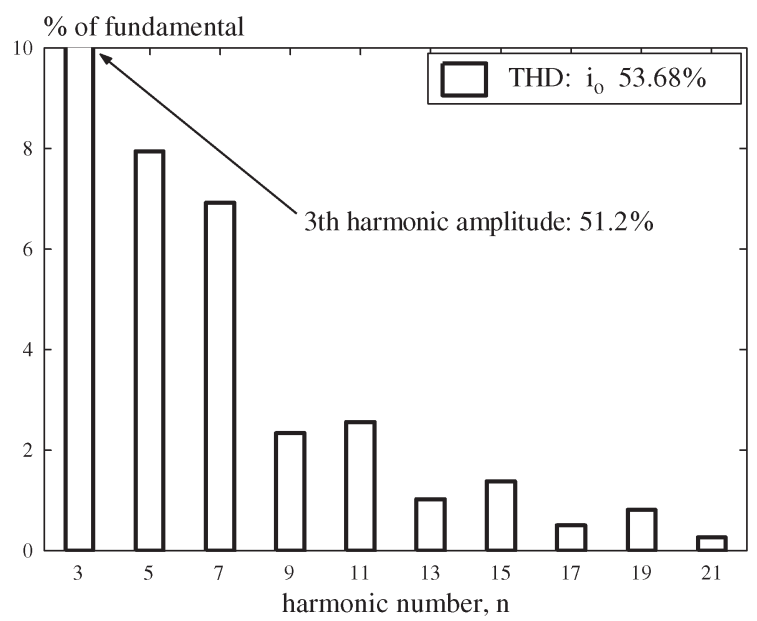

Fig. 10. Spectrum of load current $i_{o}$ with low-distorted grid.

\section{A. Experimental Setup}

An experimental active-filter prototype was built using a 4.5-kVA SEMIKRON full bridge as the power converter and a TMS320F2812 fixed-point DSP as the digital control platform.

The same parameters listed in Table I are used in the experimental analysis. The grid supplies a rectifier with an $R C$ load which presents a current crest factor of 1.94 and a power factor of 0.86 (see Fig. 9). The grid voltage is considered under two conditions: low-distorted grid with a voltage THD of $0.4 \%$ and distorted grid with a voltage THD of $3.42 \%$. In this case, the third-, fifth-, seventh-, and ninth-order harmonics have an amplitude of $2 \%$ with respect to the amplitude of the fundamental harmonic. The THD of the load current is $53.68 \%$ when the load is fed by the low-distorted grid and $46.40 \%$ when fed by the distorted grid. Fig. 10 shows the spectrum of the load current $i_{O}$.

The control schemes shown in Figs. 2 and 3 have been programmed and translated into the DSP platform. The discrete versions of the filters $H_{1}(s)$ and $H_{2}(s)$ have been derived using the Tustin transformation, with a sampling frequency of $15 \mathrm{kHz}$. It is worth mentioning that the repetitive controller has been implemented with infinite-impulse-response bandpass filters instead of the finite-impulse-response filters used in [20]. With this modification, both the proposed controller and the repetitive controller employ the same type of bandpass filters, and therefore, the performance comparison is possible. 


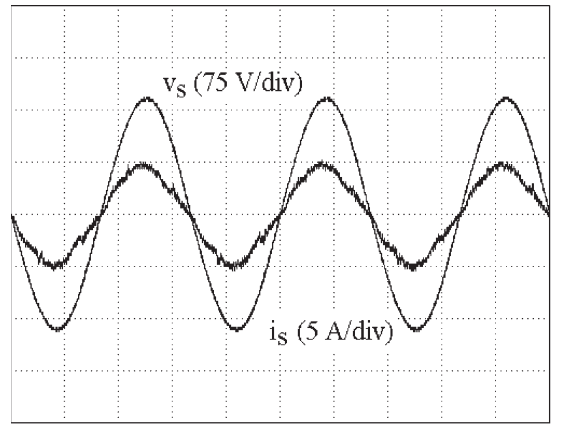

basic indirect control

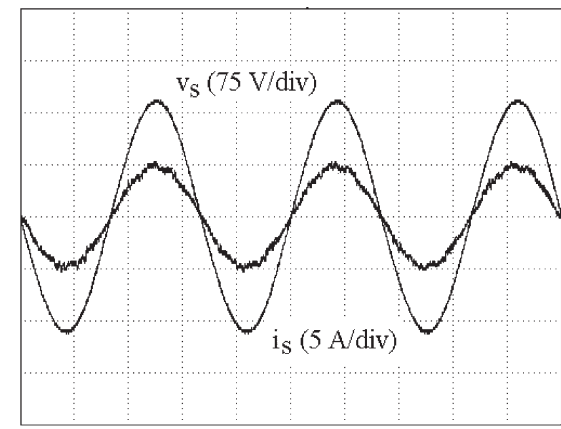

time $(5 \mathrm{~ms} / \mathrm{div})$

repetitive control

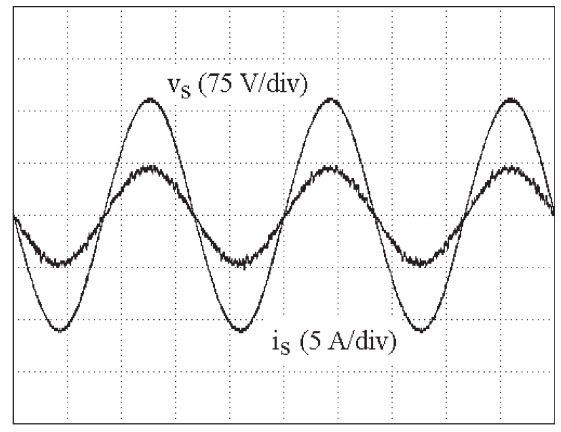

proposed control

Fig. 11. Measured results with low-distorted grid. Grid voltage $v_{s}$ and grid current $i_{s}$.

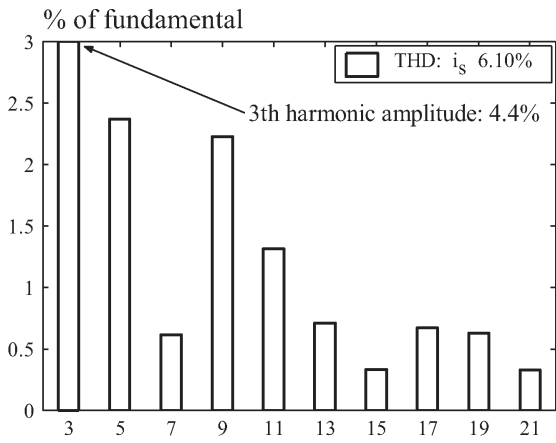

basic indirect control

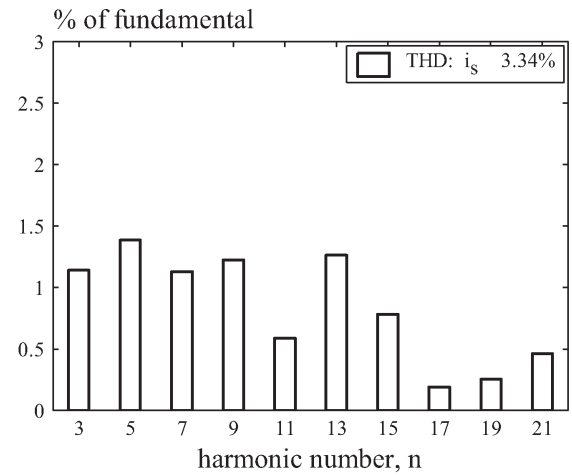

repetitive control

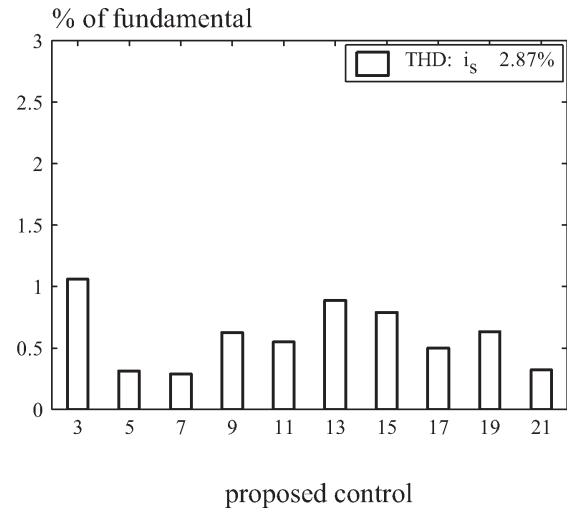

Fig. 12. Measured grid-current spectrum at low-distorted grid.

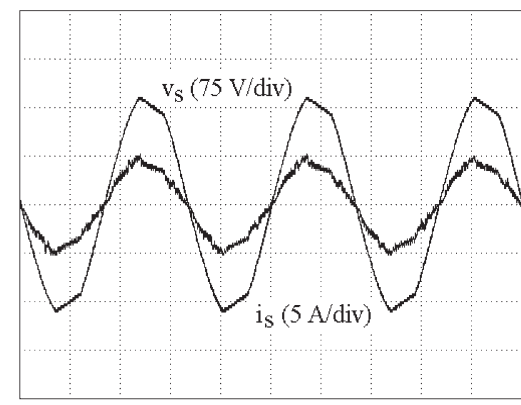

basic indirect control

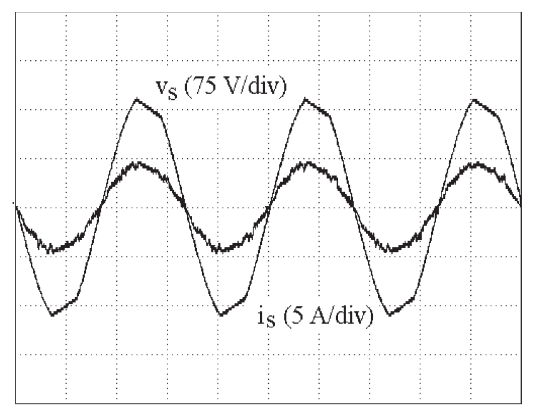

time (5 ms/div)

repetitive control

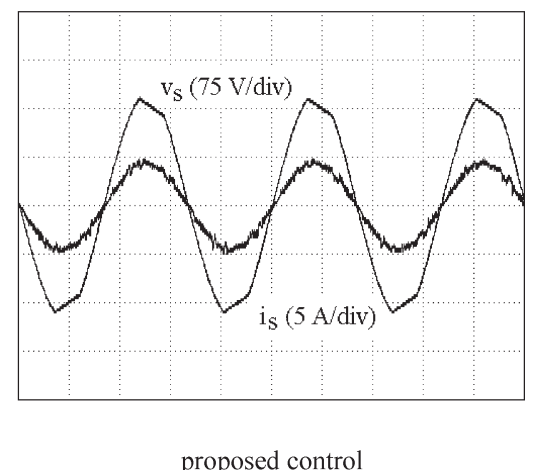

proposed control

Fig. 13. Measured results with distorted grid. Grid voltage $v_{s}$ and grid current $i_{s}$.

\section{B. Time and Spectrum Results}

Figs. 11 and 12 show the experimental results when the grid presents low-harmonic distortion. Fig. 11 shows a timewaveform comparison when using the basic indirect control, the repetitive control, and the proposed control.

Both the proposed control and the repetitive control have been designed to mitigate the third, fifth, seventh, and ninth harmonics $(h=9)$. As shown, the best time results are obtained with the proposed control. In the three controls, there is no noticeable phase deviation between the grid voltage $v_{s}$ and the grid current $i_{s}$. Fig. 12 shows the current spectra obtained with the three controls. It can be seen that the grid current THD is significantly reduced when compared with the loadcurrent THD in all the controls. The proposed control presents a superior harmonic-elimination capability in the chosen low harmonics, giving a better THD. Both the proposed and the repetitive controls present an excellent reduction of the third harmonic as compared with the basic indirect control. The per unit grid-current THD reduction, taking as a unit the gridcurrent THD obtained using the conventional control, is $46 \%$ with the repetitive control and 53\% with the proposed control.

In practical applications, the main voltage waveform is normally distorted. Fig. 13 shows the waveforms of the grid voltage $v_{s}$ and the grid current $i_{s}$ in a distorted grid. Fig. 14 shows the spectra of $i_{s}$. In both the basic indirect control and the repetitive control, the grid-current-harmonic amplitude is increased with respect to the low-distorted-grid condition. Using the proposed control, only a small increase of the harmonic amplitude is noticed, thus showing a better harmonic-rejection capability 


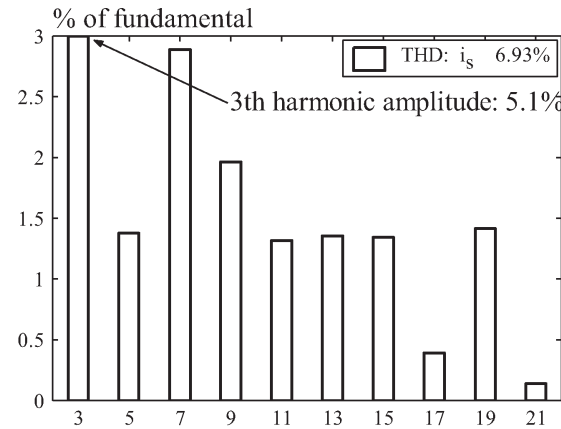

basic indirect control

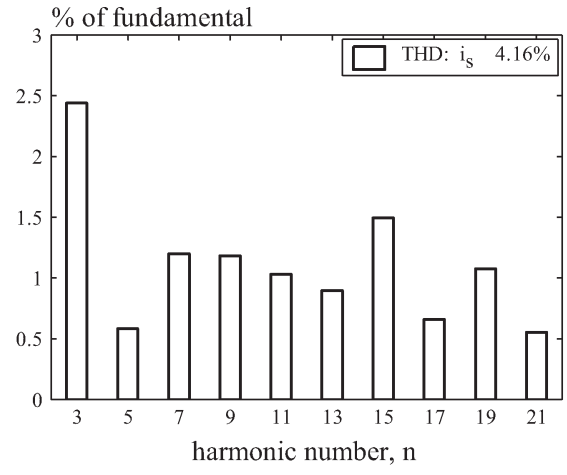

repetitive control

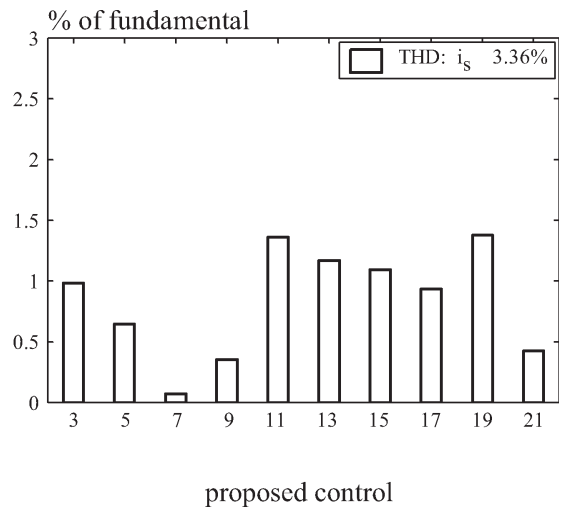

proposed control
Fig. 14. Measured grid-current spectrum at distorted grid.
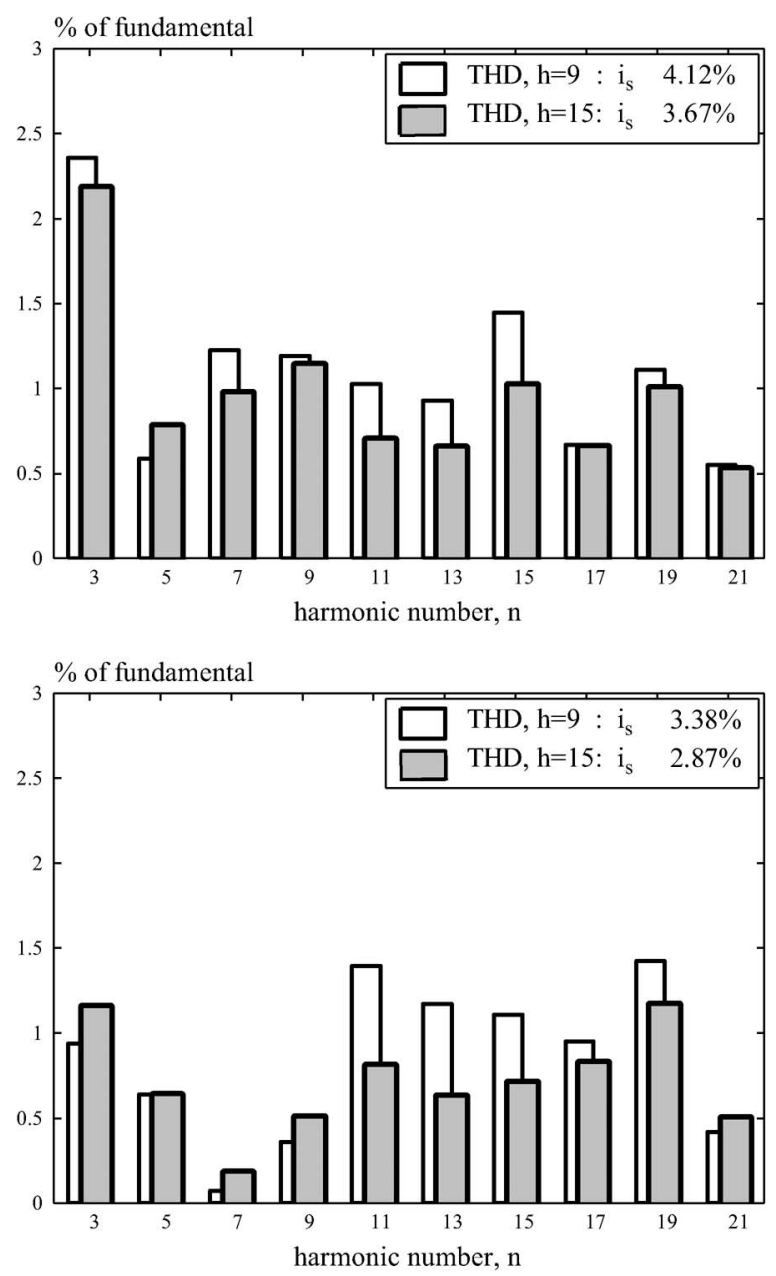

Fig. 15. Measured grid-current spectrum at distorted grid, for (top) repetitive control and (bottom) proposed control, when $h=9$ and $h=15$.

than the reference controllers. The per unit grid-current THD reduction, when compared with the one obtained using the conventional control, is $52 \%$ with the proposed control and $41 \%$ with the repetitive control. If necessary, the grid-current distortion can be reduced using more bandpass filters in the transfer function $\mathrm{H}_{2}(s)$. For example, Fig. 15 shows the gridcurrent spectra at distorted grid when $h=9$ and when $h=15$. As it can be seen, by the additional compensation of the 11th, 13th, and 15th grid harmonics, the grid-current THD is reduced using both the repetitive and the proposed controller.

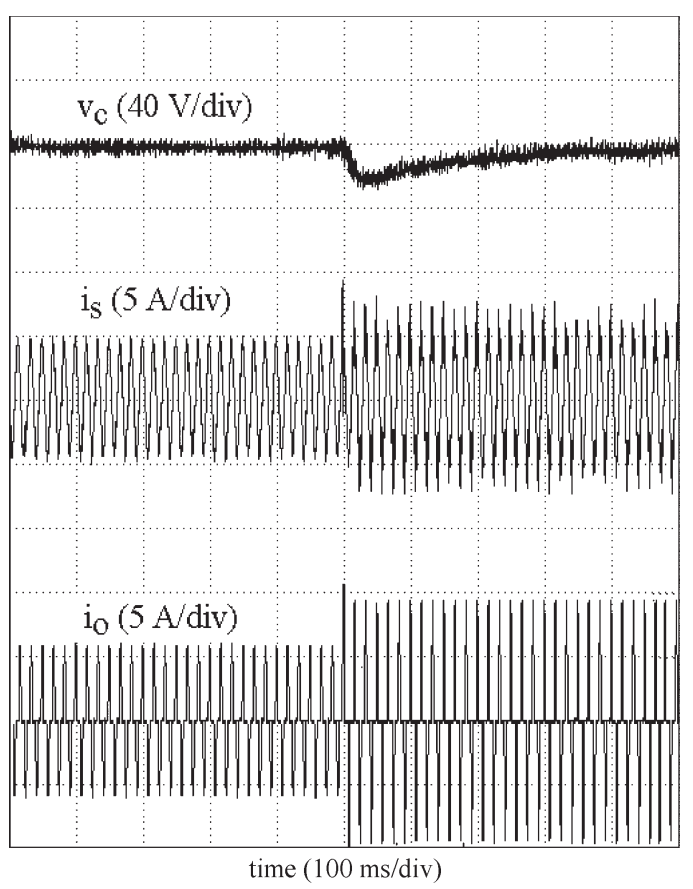

Fig. 16. Response to a step load change using the proposed control. Capacitor voltage $v_{c}$, grid current $i_{s}$, and load current $i_{o}$.

\section{Dynamic Performance}

The dynamic performance of the proposed controller was also evaluated under step load changes. Fig. 16 shows the transient response of the capacitor voltage $v_{c}$ and the grid current $i_{s}$. A step change in the load current $i_{o}$ from nominal load to $200 \%$ load is programmed. It is interesting to note that this controller maintains a sinusoidal line current even during the step change, so that a suitable grid-current transient behavior is obtained. It can be seen that the recovery time of the capacitor voltage is $400 \mathrm{~ms}$, showing the slow bandwidth of the outer voltage loop. Although not shown here, the reference controllers present a dynamic behavior with no appreciable differences with respect to the proposed controller.

\section{Grid-Frequency Variation}

The negative effects of the grid-frequency variation are also evaluated experimentally. Fig. 17 shows the measured gridcurrent distortion as a function of the grid-frequency variation. 


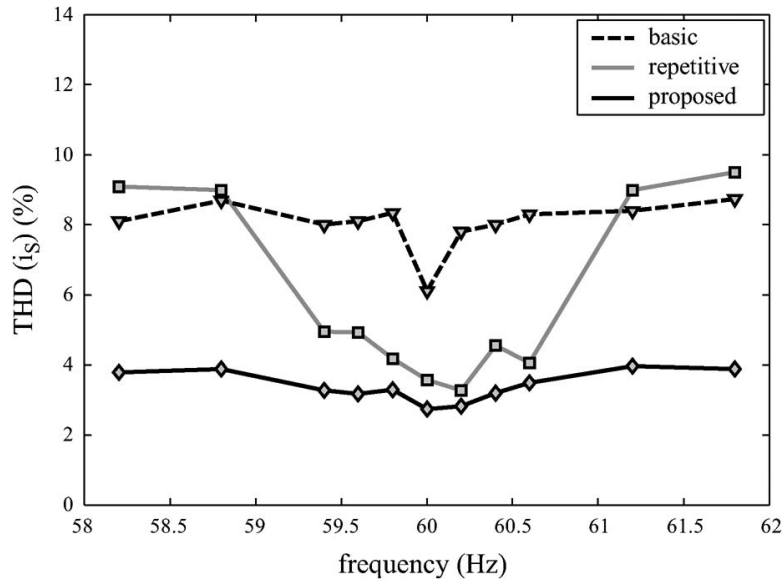

Fig. 17. Measured grid-current THD as a function of the grid frequency for basic, repetitive, and proposed controllers.

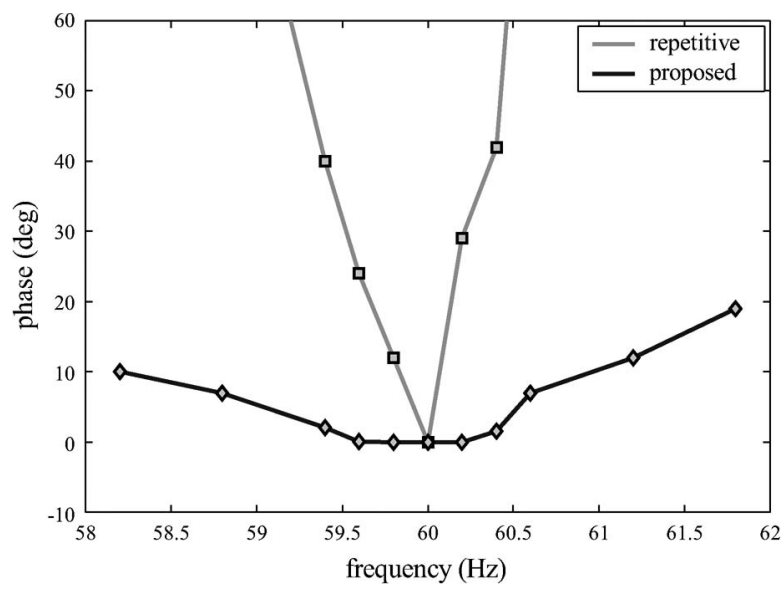

Fig. 18. Experimental phase deviation (absolute values) between grid voltage and grid current under grid-frequency variations.

As shown, the frequency deviation reduces the harmonic rejection due to the narrow bandwidth of the $H_{1}(s)$ and $H_{2}(s)$ bandpass filters. When the system is not operating at the nominal frequency, the gain of the bandpass filters is reduced, and the harmonic rejection is also reduced.

The repetitive control presents an unacceptably high variation in the current THD that considerably reduces its field of applications. The proposed solution is more robust in the harmonic rejection than the repetitive control. In fact, the THD increases only slightly when the frequency varies between 58.2 and $61.8 \mathrm{~Hz}$.

Fig. 18 shows the measured phase lag between grid voltage and grid current when the frequency presents deviations from its nominal value. The phase lag was measured by extracting the fundamental harmonic of the grid voltage and grid current and, then, comparing the zero crossing of both signals. Although not shown in Fig. 18, a zero-phase deviation is measured when using the basic indirect control, as expected. The phase deviation is significant if the grid frequency varies from its nominal value, when using either the repetitive or the proposed control. The repetitive control experiences an unacceptable phase deviation with little grid-frequency variation. Our solution is more robust, but as anticipated, if the fre- quency variation is great, the power factor is affected negatively. Therefore, an online frequency measurement that improves the bandpass filters' response should be employed in this particular situation.

\section{E. Efficiency}

The evaluated control schemes have a negligible effect on the system efficiency. At rated power, the measured efficiency is nearly $92 \%$ for the three controllers.

\section{Conclusion}

A linear current control scheme for single-phase APFs has been presented. The approach is based on an outer voltage loop, an inner current loop, and a resonant selective harmonic compensator. The design of the control parameters was carried out using conventional linear techniques (analysis of loop gain and other disturbance-rejection transfer functions). The performance characteristics of the proposed controller was evaluated and compared with two reference controllers. The comparison confirms that the proposed controller offers high reduction of the grid-current harmonics, low sensitivity to line voltage distortion, low sensitivity to grid-frequency variations, and good load transient response. The preliminary results show promising properties, and thus, this approach may be a good candidate in single-phase environments requiring such control performances.

\section{APPENDIX}

\section{SMALl-Signal Model of THE OUter Voltage Loop}

The outer voltage loop is a low-bandwidth control system that stabilizes the capacitor voltage with no degradation of the grid-current waveform. For control design purposes, a smallsignal model is derived here that correctly predicts the lowfrequency system behavior.

From the Tellegen theorem, the energy balance of the APF system, assuming no losses and negligible energy stored in the inductor, can be expressed as [33], [34]

$$
\frac{d}{d t}\left(\frac{1}{2} C v_{c}^{2}\right)=v_{s} \cdot i_{s}-v_{s} \cdot i_{o} .
$$

The input power, $v_{s} \cdot i_{s}$, is comprised of a low-frequency term, a term that varies at the second grid-frequency harmonic, and high-frequency switching ripple terms. The output power, $v_{s}$. $i_{o}$, has an even greater harmonic content. It has terms at the same frequencies as the input power as well as terms that vary at other grid-frequency harmonics.

Due to the low bandwidth of the outer voltage loop, only the low-frequency terms in (9) are required for the control design. These low-frequency terms are derived by averaging (9) over one-half of the grid period

$$
\frac{d}{d t}\left(\frac{1}{2} C\left\langle v_{c}^{2}\right\rangle\right)=\left\langle v_{s} \cdot i_{s}\right\rangle-\left\langle v_{s} \cdot i_{o}\right\rangle
$$

where $\langle\cdot\rangle$ denotes averaged variables. 
It can be assumed that the inner high-bandwidth current loop operates ideally at low frequencies, such that the grid current tracks the reference current as

$$
i_{s}=i_{\mathrm{ref}}=k(t) \cdot v_{s} .
$$

The PI compensator and the low-pass filter of the outer voltage loop can be expressed as (see Fig. 2)

$$
\begin{aligned}
k(t) & =k_{p v}\left(v_{\mathrm{ref}}^{2}-v_{c f}^{2}\right)+k_{i v} \int\left(v_{\mathrm{ref}}^{2}-v_{c f}^{2}\right) d t \\
\frac{d v_{c f}^{2}}{d t} & =\omega_{c}\left(v_{c}^{2}-v_{c f}^{2}\right)
\end{aligned}
$$

where $k_{p v}$ and $k_{i v}$ are the PI gains and $\omega_{c}$ is the crossover lowpass-filter frequency.

Taking into account that the variable $k(t)$ has a lowfrequency behavior, the following nonlinear model is derived by replacing (11) into (10):

$$
\frac{d}{d t}\left(\frac{1}{2} C\left\langle v_{c}^{2}\right\rangle\right)=k(t) \cdot\left\langle v_{s}^{2}\right\rangle-\left\langle v_{s} \cdot i_{o}\right\rangle
$$

The small-signal model can be constructed, as usual, by perturbation and linearization of (14). In the Laplace domain, the linearized model can be expressed as

$$
\begin{aligned}
\hat{v}_{c}^{2}(s) & =G_{1}(s) \cdot \hat{i}_{o}+G_{2}(s) \cdot \hat{v}_{s}+\frac{2 V_{s p}^{2}}{C s} \cdot \hat{k}(s) \\
\hat{k}(s) & =\left(k_{p v}+\frac{k_{i v}}{s}\right) \cdot\left(\hat{v}_{\mathrm{ref}}^{2}(s)-\hat{v}_{c f}^{2}(s)\right) \\
\hat{v}_{c f}^{2}(s) & =\frac{\omega_{c}}{s+\omega_{c}} \cdot \hat{v}_{c}^{2}(s)
\end{aligned}
$$

where ${ }^{\wedge}$ denotes small-signal variables, $s$ is the Laplace operator, and $V_{s p}$ is the peak value of the grid voltage. The diagram of the small-signal model is shown in Fig. 4.

\section{REFERENCES}

[1] H. Akagi, "Trends in active power line conditioners," IEEE Trans. Power Electron., vol. 9, no. 3, pp. 263-268, May 1994.

[2] H. Akagi, A. Nabae, and S. Atoh, "Control strategy of active power filter using multiple voltage source PWM converters," IEEE Trans. Ind. Appl., vol. IA-22, no. 3, pp. 460-465, May 1986.

[3] M. El-Habrouk, M. K. Darwish, and P. Mehta, "Active power filters: A review," Proc. Inst. Elect. Eng.-Elect. Power Appl., vol. 147, no. 5, pp. 403-413, Sep. 2000.

[4] M. P. Kazmierkowski and L. Malesani, "Current control techniques for three-phase voltage-source PWM converters: A survey," IEEE Trans. Ind. Electron., vol. 45, no. 5, pp. 691-703, Oct. 1998.

[5] T. C. Green and J. H. Marks, "Control techniques for active power filters," Proc. Inst. Elect. Eng.-Elect. Power Appl., vol. 152, no. 2, pp. 369-381, Mar. 2005.

[6] C. Y. Hsu and H. Y. Wu, "A new single-phase active power filter with reduced energy-storage capacity," Proc. Inst. Elect. Eng.-Elect. Power Appl., vol. 143, no. 1, pp. 25-30, Jan. 1996.

[7] H. Komurcugil and O. Kukrer, "A new control strategy for single-phase shunt active power filters using a Lyapunov function," IEEE Trans. Ind. Electron., vol. 53, no. 1, pp. 305-312, Feb. 2006.

[8] J. C. Wu and H. L. Jou, "Simplified control method for single-phase active power filter," Proc. Inst. Elect. Eng.-Elect. Power Appl., vol. 143, no. 3, pp. 219-224, May 1996.

[9] F. Pottker and I. Barbi, "Power factor correction of non-linear loads employing a single phase active power filter: Control strategy, design methodology and experimentation," in Proc. IEEE PESC, St. Louis, MO, Jun. 22-27, 1997, pp. 412-417.
[10] D. A. Torrey and A. M. A. M. Al-Zamel, "Single-phase active power filters for multiple nonlinear loads," IEEE Trans. Power Electron., vol. 10, no. 3, pp. 263-272, May 1995.

[11] V. F. Corasaniti, M. B. Barbieri, P. L. Arnera, and M. I. Valla, "Hybrid active filter for reactive and harmonics compensation in a distribution network," IEEE Trans. Ind. Electron., vol. 56, no. 3, pp. 670-677, Mar. 2009.

[12] B. N. Singh, "Sliding mode control technique for indirect current controlled active filter," in Proc. IEEE Region 5 Annи. Tech. Conf., New Orleans, LA, Apr. 2003, pp. 51-58.

[13] G. W. Chang, C. M. Yeh, and W. C. Chen, "Meeting IEEE-519 current harmonics and power factor constraints with a three-phase three-wire active power filter under distorted source voltages," IEEE Trans. Power Del., vol. 21, no. 3, pp. 1648-1654, Jul. 2006.

[14] B. Singh, V. Verma, and J. Solanki, "Neural network-based selective compensation of current quality problems in distribution system," IEEE Trans. Ind. Electron., vol. 54, no. 1, pp. 53-60, Feb. 2007.

[15] K. Shyu, M. J. Yang, Y. M. Chen, and Y. F. Lin, "Model reference adaptive control design for a shunt active-power-filter system," IEEE Trans. Ind. Electron., vol. 55, no. 1, pp. 97-106, Jan. 2008.

[16] J. Matas, L. Garcia de Vicuña, J. Miret, J. M. Guerrero, and M. Castilla, "Feedback linearization of a single-phase active power filter via sliding mode control," IEEE Trans. Power Electron., vol. 23, no. 1, pp. 116-125, Jan. 2008.

[17] B. R. Lin and C. H. Huang, "Implementation of a three-phase capacitorclamped active power filter under unbalanced condition," IEEE Trans. Ind. Electron., vol. 53, no. 5, pp. 1621-1630, Oct. 2006.

[18] R. Teodorescu, F. Blaabjerg, M. Liserre, and P. C. Loh, "Proportionalresonant controllers and filters for grid-connected voltage-source converters," Proc. Inst. Elect. Eng.-Elect. Power Appl., vol. 153, no. 5, pp. 750-762, Sep. 2006.

[19] I. Etxeberria-Otadui, A. L. de Heredia, H. Gaztañaga, S. Bacha, and M. R. Reyero, "A single synchronous frame hybrid (SSFH) multifrequency controller for power active filters," IEEE Trans. Ind. Electron., vol. 53, no. 5, pp. 1640-1648, Oct. 2006.

[20] P. Mattavelli and F. P. Marafao, "Repetitive-based control for selective harmonic compensation in active power filters," IEEE Trans. Ind. Electron., vol. 51, no. 5, pp. 1018-1024, Oct. 2004

[21] A. Garcia-Cerrada, O. Pinzon-Ardila, V. Feliu-Batlle, P. Romero-Sanchez, and P. Garcia-Gonzalez, "Application of a repetitive controller for a threephase active power filter," IEEE Trans. Power Electron., vol. 22, no. 1, pp. 237-246, Jan. 2007.

[22] P. Mattavelli, "A closed-loop selective harmonic compensation for active filters," IEEE Trans. Ind. Appl., vol. 37, no. 1, pp. 81-89, Jan. 2001.

[23] C. Lascu, L. Asiminoaei, I. Boldea, and F. Blaabjerg, "High performance current controller for selective harmonic compensation in active power filters," IEEE Trans. Power Electron., vol. 22, no. 5, pp. 1826-1835, Sep. 2007.

[24] R. I. Bojoi, G. Griva, V. Bostan, M. Guerriero, F. Farina, and F. Profumo, "Current control strategy for power conditioners using sinusoidal signal integrators in synchronous reference frame," IEEE Trans. Power Electron., vol. 20, no. 6, pp. 1402-1412, Nov. 2005.

[25] M. Castilla, J. Miret, J. Matas, L. G. de Vicuña, and J. M. Guerrero, "Linear current control scheme with series resonant harmonic compensator for single-phase grid-connected photovoltaic inverters," IEEE Trans. Ind. Electron., vol. 55, no. 7, pp. 2724-2733, Jul. 2008.

[26] H. Tao, J. L. Duarte, and M. A. M. Hendrix, "Line-interactive UPS using a fuel cell as the primary source," IEEE Trans. Ind. Electron., vol. 55, no. 8, pp. 3012-3021, Aug. 2008.

[27] M. J. Newman, D. N. Zmood, and D. G. Holmes, "Stationary frame harmonic reference generation for active filter systems," IEEE Trans. Ind. Appl., vol. 38, no. 6, pp. 1591-1599, Nov. 2002.

[28] D. N. Zmood, D. G. Holmes, and G. H. Bode, "Frequency-domain analysis of three-phase linear current regulators," IEEE Trans. Ind. Appl., vol. 37, no. 2, pp. 601-610, Mar./Apr. 2001.

[29] J. Allmeling, "A control structure for fast harmonics compensation in active filters," IEEE Trans. Power Electron., vol. 19, no. 2, pp. 508-514, Mar. 2004.

[30] U. Grossmann, T. Ellinger, G. Berger, J. Petzoldt, H. G. Mall, and G. Frako, "Active filter control in the stationary reference frame using lowpass to bandpass transformation," in Proc. PCIM, Nuremberg, Germany, May 2003, pp. 81-86.

[31] W. Lenwari, M. Sumner, and P. Zanchetta, "The use of genetic algorithms for the design of resonant compensators for active filters," IEEE Trans. Ind. Electron., vol. 56, no. 8, pp. 2852-2861, Aug. 2009.

[32] X. Yuan, W. Merk, H. Stemmler, and J. Allmeling, "Stationary-frame generalized integrators for current control of active power filters with zero 
steady-state error for current harmonics of concern under unbalanced and distorted operating conditions," IEEE Trans. Ind. Appl., vol. 38, no. 2, pp. 523-532, Mar./Apr. 2002.

[33] G. Bhuvaneswari and M. G. Nair, "Design, simulation, and analog circuit implementation of a three-phase shunt active filter using the I cosphi algorithm," IEEE Trans. Power Del., vol. 23, no. 2, pp. 1222-1235, Apr. 2008

[34] D. Casadei, G. Grandi, R. K. Jardan, and F. Profumo, "Control strategy of a power line conditioner for cogeneration plants," in Proc. IEEE PESC, Charleston, SC, Jun. 1999, pp. 607-612.

[35] L. Malesani, P. Mattavelli, and S. Busom, "On the applications of active filters to generic loads," in Proc. IEEE ICHQP, Athens, Greece, Oct. 14-16, 1998, pp. 310-319.

[36] W. Longhui, Z. Fang, Z. Pengbo, L. Hongyu, and W. Zhaoan, "Study on the influence of supply-voltage fluctuation on shunt active power filter," IEEE Trans. Power Del., vol. 22, no. 3, pp. 1743-1749, Jul. 2007.

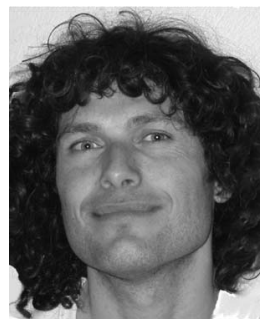

Jaume Miret (M'01) received the B.S. degree in telecommunications and the M.S. and Ph.D. degrees in electronics from the Technical University of Catalonia, Barcelona, Spain, in 1992, 1999, and 2005, respectively.

Since 1993, he has been an Assistant Professor in the Department of Electronic Engineering, Technical University of Catalonia, Vilanova i la Geltrú, Spain, where he teaches courses on digital design and circuit theory. His research interests indigital control. clude dc-to-ac converters, active power filters, and

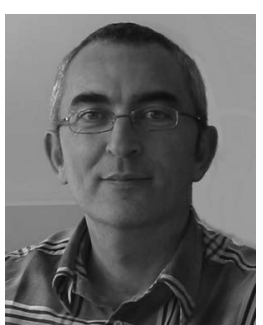

Miguel Castilla received the B.S., M.S., and Ph.D. degrees in telecommunication engineering from the Technical University of Catalonia, Barcelona, Spain, in 1988,1995 , and 1998 , respectively.

Since 2002, he has been an Associate Professor with the Department of Electronic Engineering, Technical University of Catalonia, Vilanova i la Geltrú, Spain, where he teaches courses on analog circuits and power electronics. His research interests are in the areas of power electronics, nonlinear control, and renewable energy systems.

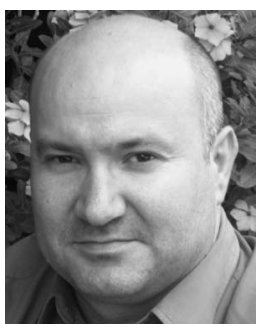

José Matas received the B.S., M.S., and Ph.D. degrees in telecommunications engineering from the Technical University of Catalonia, Barcelona, Spain, in 1988, 1996, and 2003, respectively.

From 1988 to 1990, he was an Engineer with a consumer electronics company. Since 1990, he has been an Associate Professor in the Department of Electronic Engineering, Technical University of Catalonia, Vilanova i la Geltrú, Spain. His research interests include power-factor-correction circuits, active power filters, uninterruptible power systems, distributed power systems, and nonlinear control.

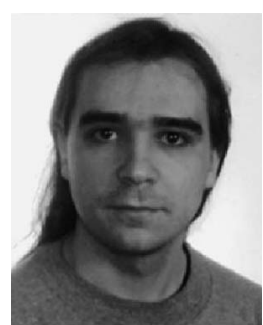

Josep M. Guerrero (S'01-M'04-SM'08) received the B.S. degree in telecommunications engineering, the M.S. degree in electronics engineering, and the $\mathrm{Ph} . \mathrm{D}$. degree in power electronics from the Technical University of Catalonia, Barcelona, Spain, in 1997, 2000 , and 2003, respectively.

$\mathrm{He}$ is currently an Associate Professor in the Department of Automatic Control Systems and Computer Engineering, Technical University of Catalonia, where he currently teaches courses on digital signal processing, field-programmable gate arrays, microprocessors, and renewable energy. Since 2004, he has been responsible for the Renewable Energy Laboratory, Escola Industrial de Barcelona. His research interests include photovoltaics, wind-energy conversion, uninterruptible power supplies, storage energy systems, and microgrids.

Dr. Guerrero is the Editor-in-Chief of the International Journal of Integrated Energy Systems. He is also an Associate Editor for the IEEE TRANSACTIONS on Industrial Electronics, the IEEE Transactions on Power ELECTRONICS, the International Journal of Power Electronics, and the International Journal of Industrial Electronics and Drives.

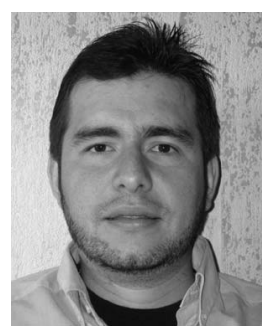

Juan C. Vasquez received the B.S. degree in electronics engineering from the Universidad Autonoma de Manizales, Manizales, Colombia, in 2004. He is currently working toward the Ph.D. degree in the Department of Automatic Control Systems and Computer Engineering, Technical University of Catalonia, Barcelona, Spain.

He was an Assistant Professor at the Universidad Autonoma de Manizales, where he taught courses on digital circuits, servo systems, and flexible manufacturing systems. He is also currently teaching courses on renewable energy systems at the Technical University of Catalonia. His research interests include modeling, simulation, photovoltaics, and descentralized control techniques applied to distributed generation in microgrids. 